\title{
ARE GEOGRAPHER'S RESEARCH METHODOLOGIES REALLY POOR?
}

\author{
Hriday L Koirala*
}

\begin{abstract}
Research methodology is closely associated with both philosophy and paradigm of a discipline. Paradigms are combinations of law, theory and methodology. Philosophy critically assesses the objectives of the explanation and how they are achieved. Theory is used to create the bases for the explanation. Therefore, it is utmost necessary to tie up theories/concepts, philosophy and methodology in an academic research. Most of the doctoral research works of Nepal in human geography are either entirely empiricist/positivist or unaware of these 'isms' in geography, yet, there are several researches which characterize a very good theoretical, philosophical and methodological basis. Similarly, the analysis techniques of the geographers typify a vivid characteristic as used in other parts of the world.
\end{abstract}

\section{INTRODUCTION}

How should methodological questions be studied and discussed? Although Hartshorne initiated the discussion in 1947 at the annual meeting of American geographers, yet, it could be regarded as a hidden agenda within the discipline that is known as Geography. In the words of Hartshorne (2002), the geographers in doing research and writing those did not take methodology as seriously as they do their "real scientific work". Further, he questions, have they any reason to suppose that their substantive work will have a greater influence in geography than their methodological writings? Therefore, it is both appropriate and desirable that any methodological writing worthy of publication should be subjected to critical evaluation in terms of its basic assumptions, the reliability of its evidence and the soundness of its logical reasoning.

Methodology deals with information collection, processing, organization as well as analysis techniques (Johnston, 1984). However, the methodology is not independent of grounds of belief or our prevailing values which exist in our society at the present time. The beliefs upon which we rest the objectives of our study (what) form our philosophy: our own individual view of life and living. It is convenient, therefore, to designate the manifestation of these beliefs in geographical work as the philosophy of geography (Harvey 1969). There are many such philosophies, varying from country to country, from group to group, and over time; each with distinctive view of nature of geography. Therefore, methodology is guided by the philosophies and no research takes place in a philosophical vacuum.

The history of geographical thought shows that the discussion of philosophical/methodological issues had stated since 1930s particularly in AngloAmerican human geography. Richard Hartshorne's The nature of Geography emphasizing 'aerial differentiation' and the regional character of geographical

\footnotetext{
*Associate Professor, Central Department of Geography, Tribhuvan University, Kirtipur, Nepal
} 
study was seen as advocating an 'ideographic' method that eschewed the development of laws in geography (Gregory 1978 as cited in Paterson, 1984). During the 1950s, a 'spatial science' approach was developed and debate continued on the nature, scope and objects of geography in the light of the then new approach (for example, Ackerman 1963, Berry 1964a, Brookfield 1964 as cited in Paterson 1984). The importance of the spatial approach lies in the fact that it has led to a noticeable tendency for 'geographical philosophizing'. In this connection, David Harvey's (1969) Explanation in Geography, a book which received wide popularity, could be regarded as the foundation for the academic discussion in developing research methods and explanation. The criticism of spatial science also came from other geographers who were dissatisfied with what they considered to be its often implicit neo-classical economic assumption (Johnston 1996). The early 1970s witnessed behavioral approach, emphasizing aggregative spatial behavor and decision making. During the same time, the debate initiated by Area, a journal of the Institute of British Geographers, within geography for relevant research to the solution of urgent social problems helped to mobilize a group of American human geographers with a radical political and philosophical perspective (Smith 1971). Further, during 1980s criticism of spatial science was introduced from several philosophical forums under a broad umbrella of 'humanistic approach' which included phenomenology, existentialism and idealism. All the debates and discussions that took place in the discipline since 1947s, led Anglo-American human geography as well as geography of other parts of the world to move into a period of philosophical and methodological pluralism which remains in the intellectual arena of the discipline still today.

With this context, the present paper aims to evaluate the available doctoral (Ph.D.) researches in order to explore their philosophical and methodological strengths. The basic thrust of writing this paper on the research methodological issue is to contextualize the Hartshorne's paradox as well as evaluate the development of Nepalese geography with respect to the "World context".

\section{MATERIALS}

All the doctoral dissertations in geography that are available in the Central Library of Tribhuvan University, Nepal have been selected as the materials to evaluate the issue discussed in earlier section. Altogether, there were thirty $\mathrm{PhD}$ dissertations which have been awarded degree by sixteen different universities of five countries namely UK, USA, Australia, India and Nepal (Table 1). It covers dissertations of both foreigners as well as Nepali scholars. Although Ranjitkar (2006) has mentioned completion of doctoral research by 47 Nepalese geographers, but these all were not available in the library. This unavailability has excluded the evaluation of dissertations of some of the notable geographers such as Amatya, S.L; Shrestha, C.B; Manandhar, M.S; Shrestha, Nanda; Pradhan, P.K; Thapa, Poonam etc. Similarly, several other geographers from foreign countries too pursued doctoral researchers on various issues of Nepal. The paper is limited to the research reports shown on Table 1 which were available in the Tribhuvan University Library during the survey period. Therefore, the generalizations and explanations that are made in this article reflect the characteristics of only those 30 dissertations. 
However, the library could be regarded rich in terms of research report's spatial coverage of the universities. It has collection of dissertations from three UK universities (Edinburgh, Oxford and Leeds), five in USA (California, Hawaii, Pittsburgh, Texas and Cornell), six of India (BHU, Patna, Delhi, Allahabad, Kumaon and Gauhati) and one each from Australia (ANU) and Nepal (TU). It has the collection of dissertations of last 41 years (1965-2006). Four (13.3\%) among the thirty researchers are foreigners but choose different parts of Nepal as their study area, while, two Nepalese scholars (6.7) selected study area outside the country. Among the universities, Banaras Hindu University (BHU) is credited for larger numbers of doctoral scholars in geography.

\section{RESULTS AND DISCUSSIONS}

The followings are the important points that are drawn from the evaluation of the doctoral researches available in the library.

\section{NATURE OF ISSUES COVERED UNDER THE DOCTORAL RESEARCH}

The analysis of issues covered under doctoral research produces a wide range of themes under regional geography, physical geography, human geography and a overlapping. There are scanty works on confining strictly on issues of regional and physical geography. Gurung (1965), Sharma (1979) and Shrestha (1999) initiated $\mathrm{PhD}$ researches on the combinations of regional and physical geography. The rest of the dissertations are concentrated in analyzing different issues of human geography in relation to environment in different capacity.

Several researches focus themselves on different issues of environment and stood as human ecological study as well. Joshi (1972) and Gautam (2000) initiated the evaluation of urban environment of Kathmandu from the perspective of socioeconomic ecology and human health. Similarly, Brower (1987), Manadhar (1988), Stevens (1989), Russel (1992) and Koirala (2006) attempted to evaluate environment and interaction of inhabiting communities from human ecological perspective choosing different localities of Nepal as case studies. Brower (1987) and Stevens (1989) evaluated cultural ecology of the highland Sherpas living in Khumbu area with issues of livestock and subsistence farming. On the other hand, Manandhar (1988) attempted to challenge on myths of eco-crisis in Nepal choosing middle hills of Nepal as the study area. Similarly, Koirala (2006) attempted to explore and analyze the livelihoods and adaptive strategies of the communities living in southern part of Arun valley in relations to sustainability.

A large numbers of researches (27\%) are covered under natural resources: its consumption, management, planning and development as well. KC (1977) attempted spatial diffusion analysis of public policy innovations in relation to the modernization in the United States. Similarly, Sharma (1979) investigated the association between commercial energy usage and macro-socio-economic processes in 45 developed and less developed countries of the world. KC (1992) focuses on environmental stress of basic needs in a part of the country. Similarly, Yadav (2004) and Rijal (2006) evaluate community forestry and water resources in terms of livelihood and rural development in parts of eastern and western regions.

Three of the researches assessed the mobility pattern of Nepali people Kansakar (1974) was named as the first scholar to examine the population change of 
Nepal from 1911 to 1961. Similarly, Subedi (1993) attempted to evaluate the forms and extent of territorial mobility between caste and ethnicity in an eastern Nepali village, whereas, Awasthi (2005) focused on the analysis of demographic and socioeconomic characteristic of migrants in Far-West Nepal. Likewise, Basnet (1992), Gnawali (1999) and Lamichhance (2003) evaluated various facets of socio-economic characteristics and resource bases of hill and Tharu communities.

The issues on agriculture and land cover/use are the focus of four Nepali researchers. Ranjitkar (1983), Khanal (2002) and Oli (2002) made in-depth studies on land use dynamics in urban Kathmandu, land cover/use in Madi Watershed and land use change in Begnas-Rupa lake watershed respectively. On the other hand, Adhikari (1995) made an in-depth diagnosis of semi-substance farming system and the processes of agrarian restructuring in the middle hilly region of Nepal.

There are very few researches strictly confining on other aspects of economic geography such as tourism, industrial and transportation geography. Upadhyaya (1988) attempted to evaluate industrialization in Nepal with case of Hetuada Industrial District. Similarly, Poudel (1996) made an in-depth study of tourist resources and environmental appraisal in Pokhara region. Griesbaum (2003) evaluated transport network in relation to the rural centers of parts of Central Development Region.

Primary data is the major source of almost all the researchers which they obtained from different localities of Nepal adopting different methods. In this process, most of the researchers choose their study area within the hilly regions of Nepal and even within the hill region, Pokhara and its surrounding areas attracted more than one third of the total researchers.

\section{METHODOLOGICAL STRENGTH OF THE DOCTORAL RESEARCHES}

The methodological peculiarities are significant among the dissertations of different universities. One of the distinct peculiarities is that still there is domination of quantitative data. It may not be exaggerations to say that the research work of geography in Nepal using qualitative research methodology has yet to see the dawn as Subedi (2005) concluded. Similarly, in most of the cases data production methods are equated as the methodology. Methodology in research within physical geography to which the most of the existing researches belong could have linked methodologies in relation to the existing philosophies. The evaluation shows that except few cases, there was ignorance on philosophical basis in devising research methodology.

On philosophical-methodological basis: Subedi (2005) concluded that most of the doctoral research works of Nepal are either entirely based on empiricism/positivism or unaware of these 'isms' in geography. It is not uncommon to see the doctoral researches prior to 1980s influenced and guided by positivism/quantitative model. The study of Kansakar (1974) on population change in Nepal is relied on census data and quantitative analysis to know migration trends. In this context, Joshi (1972), KC (1977) and Sharma (1979) are credited for substantive works using different rigorous statistical techniques to evaluate the issues they had incorporated. The research of Joshi (1972) is based on the survey of 1,256 households ( $4.2 \%$ of the total) that identified through 
stratified sampling in the study area. Likewise, KC (1977) evaluated 100 public policies in respect to the data obtained through program offices and interviewing the policy makers. Similarly, Sharma (1979) used secondary data from different governmental sources to evaluate use of energy and societal development of different countries of world. Except few cases, even after the development of different philosophical bases and interrelated methodologies in human geography, still today it is common to observe same traditions as earlier.

Although, Brower (1987), Manandhar (1988) and Stevens (1989) are credited for use of both qualitative as well as quantitative methods in their researches in later part of 1990s; they have not indicated the philosophical basis in adopting the methods. The study of Brower was based on completely qualitative data generated through observation, independent enquiry and interpreter assisted discussion. Similarly, Stevens adopted oral history as insider's perspective to explore changing individual cultural perception/ knowledge/decision making, individual interview and observation to evaluate pastoral practices and mapping. In doing so, he used a three months reconnaissance for familiarity/rapport building out of the 14 months long field work. However, Manandhar's research used a mixed method with household questionnaire survey and key informant survey, participant observation and informal interview as an insiders approach in three villages with different culture. It would be worthy to mention here that all three researchers were affiliated with American universities. Similarly, Russell (1992) made a research on the interrelationship of culture, environment and development of the Yakha community of eastern Nepal but it is more oriented as anthropological than the geographical research.

Among the researchers, Subedi (1993) could be named as the first scholar to mention the philosophies adopted in his methodology although no clear cut linkage of the used methods in relation to the philosophy was made. However, he uses several research methods such as a household census survey, a mobility register, an economic survey, a life history survey, participant observation and focused group discussion within two settlements of Ilam District.

Koirala in 2006 attempted to devise a methodology based on three popular philosophical approaches and accomplished by using quantitative as well as qualitative methods and techniques. In order to evaluate the livelihood pattern, adaptive strategies and sustainability of the local people, the study attempts to take advantages of all the three approaches: positivism to generalize the phenomena, humanism to analyze the individual decisions and structuralism to understand the structure, process and pattern of phenomena operating in the area.

Except the researches discussed so far, almost all the other doctoral researches in human geography completed after 1990s have a trend of using primarily quantitative data generated through questionnaire survey, remote sensing and available maps. Therefore, based on the evaluation of 30 doctoral researches, a generalization could be made confirming Subedi's conclusion that Nepali geographers completely base and rely on positive quantitative approach knowingly/unknowingly so far.

On clear cut elaboration of research methodology: In this section, an attempt has been made to evaluate the geographer's research methodologies in terms of 
Hartshorne's statement that geographers pay less attention as well as not narrate methodology seriously as they do their "real scientific work". However, the evaluation of available doctoral researches of geographers in Nepal firmly rejects the assumption made by Hartshorne. Except few cases, almost all the researchers had paid their attention on elaboration of methodological details in their dissertation. In this connection, the works of Joshi (1972), KC (1977), Sharma (1979), Ranjitkar (1983), Manandhar (1988), Subedi (1993), Adhikari (1995), Jnawali (1999), Poudel (2001), Karerira (2001), Khanal (2002), Yadav (2004), Koirala (2006) and Rijal (2006) could be cited as good examples.

On use of data analysis techniques: Data analysis involves organization of the primary numerical information collected through different methods and/or the secondary data as well as making sense of the qualitative data. It is crucial aspect of research methodology and one must also plan to choose appropriate techniques to analyze the data (Koirala 2009a). The analysis techniques for quantitive data are different from qualitative data. Statistical or mathematical analysis, spatial analysis, functional/morphometric analysis (shape and forms in space/market centers/central place and drainage characteristics) are commonly used analysis techniques in geography. Nowadays, there are different software program to analyze both quantitative and qualitative data. SPSS, MINITAB and Microsoft Excel programs are widely used for quantitative data. A computer package known as NUD-IST is specifically designed to aid qualitative data analysis. There is also a trend to analyze some aspects of qualitative data using quantitative techniques. Similarly, cognitive description (descriptive method), cause and effect analysis, analysis by classification (Venn diagram/set theory), reading, coding, displaying, reducing and interpretation are common techniques for qualitative data (Koirala 2009b). However, the two analysis methods have blurred the demarcation. Moreover, now a days remote sensing (RS) and geographical information system (GIS) have been extensively used in mapping and analyzing the problems of land use dynamics, natural resource management and in evaluating the indicators of different issues related with space.

Joshi (1972), KC (1977), Sharma (1979) and Khanal (2002) are credited for substantive works using factor analysis, correlation, multivariate analysis and path analysis. Likewise, Brower (1987), Manandhar (1988), Stevens (1989), Subedi (1993), Adhikari (1995), Yadav (2004) and Koirala (2006) made extensive use of RS and GIS tools to analyses spatio-temporal characteristics of resources of different localities. Therefore, the analysis techniques of the geographers typify a vivid characteristics ranging from a few to all available analysis techniques used in other parts of the world as well.

On theoretical/conceptual aspect: No research is done on the premises of theoretical or conceptual vacuum. Therefore, an important task of an academic researcher is to link research issues with the existing but related concepts or theories (Koirala, 2009b). Here, theory is taken to be a set of explanatory concepts that are useful for explaining a particular phenomenon, situation or activity. These concepts offer certain ways of looking at the world and are essential in defining a research problem. According to Subedi (2005), major weakness of native geographic research works in Nepal is lack of theoretical rigor. The evaluation of the available doctoral researches produce a mixed opinion on conceptual/theoretical basis. 
Much credit goes to Sharma's (1979) research for developing a theoretical model for identification and justification on energy use and potential output variables. Similarly, the research carried out by Manandhar (1988) could be named for its challenge and justification against western percepts on myth of eco-crisis in Nepal. Likewise, Subedi (1993) developed a rural Nepali typology of mobility - the completely different form than as perceived in literatures of western perspectives. Adhikari (1995) produced a native model on the process of agrarian restructuring that has occurred in the middle hill region of Nepal. Similarly, Poudel (2001) and Khanal (2002) tried to align their researches in relation to the existing concepts on resource utilization and land use/land cover in other parts of the world. Kareriya (2001) made good attempt to devise models on rural development of Nepal. Likewise, Koirala (2006) attempted to develop a model of sustainability which is likely to differ at community level over space particularly in the context of rural mountainous environment.

The evaluation of existing researches indicates a symptom of positive beginning. However, the future geographic research in Nepal needs to be more analytical, theoretically sound and innovative so that it not only helps expand the horizon of the discipline but also address the contemporary issues of Nepalese society as Subedi (2005) concurrently envisaged.

\section{CONCLUSIONS}

An academic discipline undertakes research within a framework provided by a philosophy which contains a framework of both an epistemology and ontology together with methodology. The major philosophical, methodological and theoretical viewpoints in a discipline at any given time constitute the thought of that discipline. Therefore, it is utmost necessary to tie up theories/concepts, philosophy and methodology in an academic research.

Geographers of Nepal are pursuing their doctoral researches in a wide range of themes under regional geography, physical geography, human geography and an overlapping. Although most of the doctoral research works of Nepal within human geography are either entirely empiricist/positivist or unaware of these 'isms' in geography, there are several researches which characterize a very good theoretical, philosophical and methodological basis. However, the research methodologies of Nepalese geographers stand firmly positive in relation to Hartshorne's remark that geographers pay less attention as well as not narrate methodology seriously as they do their "real scientific work".

The evaluation of the available doctoral researches of Nepalese geographers indicates a symptom of positive beginning on conceptual/theoretical basis. Several researchers attempted to establish new concepts or generalization or models that explain contemporary human environment interaction as well as challenge and justify what has been established in the past from the empirical findings from different perspectives. However, the future geographical research in Nepal needs to be more innovative, analytical and theoretically sound to address the contemporary issues of Nepalese society as well as replicate the reality in the archives of knowledge. 


\section{WORKS CITED}

Adhikari, J. 1995. Ethnicity, Off-farm Income and Resource Use in the Semisubsistence Farming System of Kaski District, Nepal. Ph.D. Dissertation, Australian National University, Australia.

Awasthi, N. 2005. Demographic and Socio Economic Characteristics of Migrants: A Study of Kanchanpur District in the Far-western Tarai of Nepal. Ph.D. Dissertation. Kumaon University, India.

Basnet, K. 1992. Population Pressure and Responses in Terrace cultivation: A Study of Begnas Tal, Rupa Tal Watershed. Ph.D. Dissertation. Banaras Hindu University, India.

Brower, B.A. 1987. Livestock and Landscape: the Pastoral System of Sherpa in Sagarmatha National Park, Nepal. Ph.D. Dissertation. University of California, USA.

Gautam, D.R. 2000. Urban Environment and Human Health in Kathmandu Metropolis. Ph.D. Dissertation. Banaras Hindu University, India.

Griesbaum, M.T. 2003. Rural Centers and Integrated Transport Network in Nepal, Lesson Drawn from North Eastern Part of Central Development Region. Ph.D. Dissertation. Tribhuvan University, Nepal.

Gurung, H.B. 1965. Pokhara Valley, Nepal Himalaya: A Field Study in Regional Geography. Ph.D. Dissertation. University of Edinburgh, UK.

Hartshorne, R. 2002. On the Mores of Methodological Discussion in American Geography. pages 492-505 in The Nature of Geography. Reprint Rawat Publications, New Delhi.

Harvey, D. 1969. Explanation in Geography. Arnold, London.

Harvey, M.E. and Holly, B.P. (editor), 1981. Themes in Geographic Thought. Croom Helm, London.

Jnawali, D. 1999. The Tharus of Bardiya District in Nepal Tarai: A Study of Ecological and Population Perspectives. Ph.D. Dissertation. Banaras Hindu University, India.

Joshi, T.R. 1972. Exploration of the Socioeconomic Ecology of Kathmandu: Nepal. Ph.D. Dissertation. Pittsburgh University, USA.

Johnston, R.J. 1996. Geography and Geographers: Anglo-American Human Geography since 1945. Arnold, London.

Johnston, R.J. 1984. Philosophy and Human Geography: An Introduction to Contemporary Approaches. Arnold, London.

Kansakar, V.B. 1974. Population Change in Nepal: A Study of Mobility during 1911-1961. Ph.D. Dissertation. Patna University, India.

Kareriya, B.R. 2001. Rural Development and Planning in Lumbini Zone of Western Development Region of Nepal. Ph.D. Dissertation. Banaras Hindu University, India.

KC, B.K. 1977. The Sjpatial Diffusion of Public Policy Innovation and the Role of Modernization in the United States 1870-1970. Ph.D. Dissertation, University of Texas, USA. 
KC, K. 1992. Environmental Stress of Basic Needs: A Study of Begnas Tal - Rupa Tal Watershed Area, Pokhara Valley, Nepal. Ph.D. Dissertation. Banaras Hindu University, India.

Khanal, N.R. 2002. Land Use and Land Cover Dynamics in the Himalaya: A Case Study of the Madi Watershed, Western Development Region Nepal. Ph.D. Dissertation. Tribhuvan University, Nepal.

Koirala, H. L. 2009a. Shifting Paradigm in Geographical Research. In P.K. Pradhan (ed.). Geographic Research Methods Handbook. Central Department of Geography, Kathmandu.

Koirala, H.L. 2009b. Developing a Research Design in Human Geography. In P.K. Pradhan (ed.). Geographic Research Methods Handbook. Central Department of Geography, Kathmandu.

Koirala, H.L. 2006. Livelihood Pattern, Adaptive Strategy and Sustainability of Communities in Southern Arun Valley of Nepal Himalaya. Ph.D. Dissertation. University of Gauhati, India.

Lamichhane, P.R. 2003. Demographic and Socio-economic characteristics of Tharu Bonded Labour in Banke District of Nepal. Ph.D. Dissertation. Allahabad University, India.

Manadhar, S. 1988. Beyond the Myth of Eco-crisis in Nepal: Local Responses to Pressure on Land in the Middle Hills. Ph.D. Dissertation. University of Hawaii, USA.

Oli, K.P. 2002. Land use Change Dynamics: A Case Study of Begnas and Rupa Lake Watershed Area of Kaski District, Nepal. Ph.D. Dissertation. Tribhuvan University, Nepal.

Paterson, J.L. 1984. David Harvey's Geography. Croom Helm, London.

Pokharel, K.P. 2004. Local Efforts on Resource Conversation and Ecodevelopment: A Case Study of Mid Western Development Region, Nepal. Ph.D. Dissertation. Banars Hindu University, India.

Poudel, K.P. 2001. Resource Utilization and Management Strategy in the Selected Watersheds of Annapurna Region, Central Nepal. Ph.D. Dissertation. University of Delhi, India.

Poudel, P.C. 1996. Tourist Resources and Environmental Appraisal in Pokhara Region Nepal: A Geographical Analysis. Ph.D. Dissertation. Banaras Hindu University, India.

Ranjitkar, N.G. 2006: Geographers in Academic Research in Nepal, Pages 10-23 in B.P. Subedi, P.C. Poudel, K.P. Poudel (ed.). Geography in Nepal: Mountain Environment and Human Activities. Central Department of Geography, Nepal Geographical Society and NCCR North-South, Kathmandu.

Ranjitkar, N.G. 1983. Change in Agricultural Land Use and Land Value in Urban Fringe of Kathmandu City. Ph.D. Dissertation. Tribhuvan University, Nepal.

Rijal, S.P. 2006. Water and Livelihoods in Mountain Areas: A Case of Modi Watershed, Nepal. Ph.D. Dissertation. University of Oxford, UK.

Russell, A. 1992. The Yakah: Culture, Environment and Development in East Nepal. Ph.D. Dissertation. Tribhuvan University, Nepal. 
Sharma, P. 1979. Energy Consumption and Societal Development: A Cross National Causal Analysis 1960-1970. Ph.D. Dissertation. Cornell University, USA.

Shrestha, B. 1999. Mass Wasting Hazards in Parts of Upper Seti-Gandaki Drainage Basin in Kaski, Nepal. Ph.D. Dissertation. Banaras Hindu University, USA.

Smith, D.M. 1971. Radical Geography-the Next Revolution. Area 3: 153-57.

Stevens, S.F. 1989. Sherpa Settlement and Subsistence: Cultural Ecology and History in Highland Nepal. Ph.D. Dissertation. University of California, USA.

Subedi, B.P. 2005. A Glimpse of Geographic Research in Nepal: Review and Reflection, Pages 85-103 in B.P. Subedi and P.C. Poudel (eds.). Geography and Geographers' Work in Nepal: Reflections on Mountain Environment and Human Activities. Central Department of Geography, Nepal Geographical Society and NCCR North-South, Kathmandu.

Subedi, B.P. 1993. Continuity and Change in Population Movement: From Inside a Rural Nepali Community. Ph.D. Dissertation. University of Hawaii, USA.

Upadhyaya, B. 1988. Industrialization in Nepal: A Case Study of Hetauda Industrial District. Ph.D. Dissertation. Patna University, India.

Yadav, N.P. 2004. Forest User Groups in Nepal: Impacts on Community Forestry Management and Community Development. Ph.D. Dissertation. University of Leeds, UK.

\section{APPENDIX}

Table 1. Universities, numbers, names and years of Ph.D. report submission

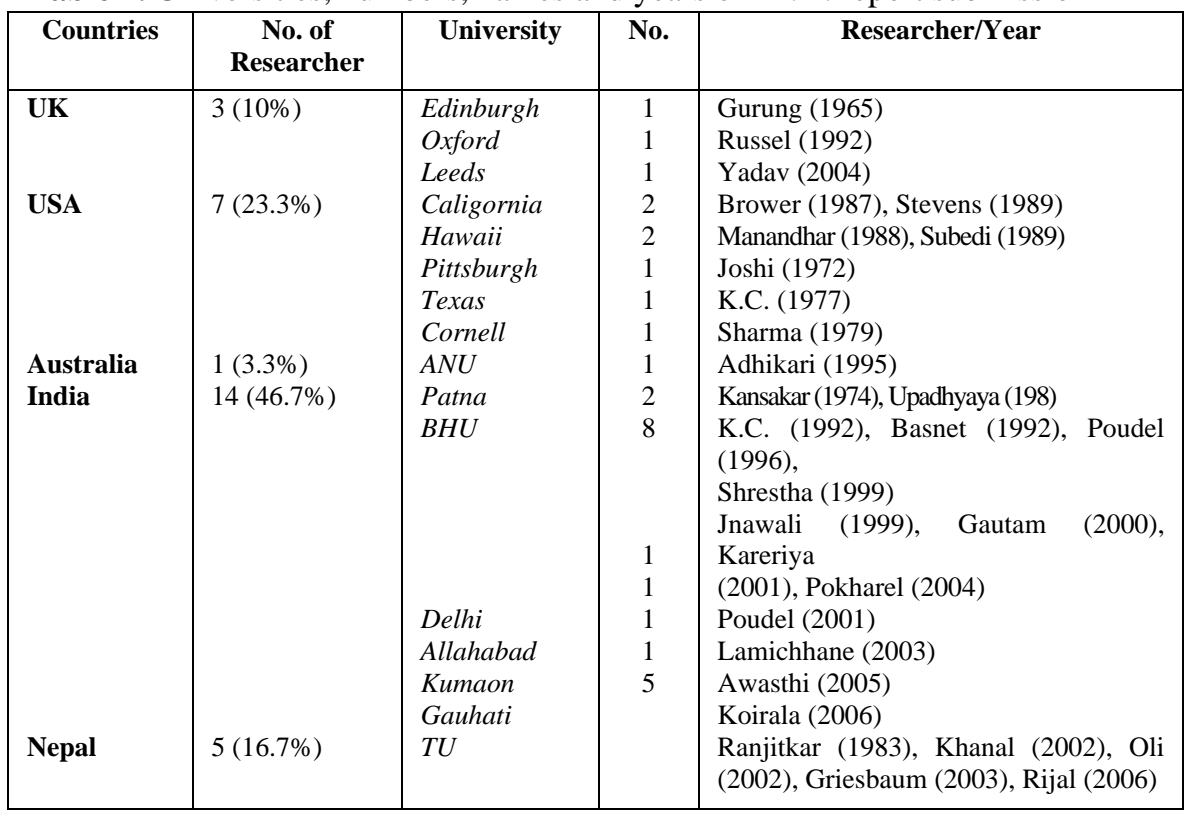

Source: Central Library of Tribhuvan University, Nepal.

Note: The list of dissertations contains only those which were available by August 2009 